Fast-track vs. delayed insertion of the levonorgestrel-releasing intrauterine system after early medical abortion - a randomized trial

Korjamo, Riina

2017-11

Korjamo , R , Mentula , M \& Heikinheimo , O 2017 , ' Fast-track vs. delayed insertion of the levonorgestrel-releasing intrauterine system after early medical abortion - a randomized trial ', Contraception , vol. 96 , no. 5 , pp. 344-351 . https://doi.org/10.1016/j.contraception.2017.07.008

http://hdl.handle.net/10138/298095

https://doi.org/10.1016/j.contraception.2017.07.008

publishedVersion

Downloaded from Helda, University of Helsinki institutional repository.

This is an electronic reprint of the original article.

This reprint may differ from the original in pagination and typographic detail.

Please cite the original version. 


\title{
Fast-track vs. delayed insertion of the levonorgestrel-releasing intrauterine system after early medical abortion - a randomized trial
}

\author{
Riina Korjamo, Maarit Mentula, Oskari Heikinheimo* \\ Department of Obstetrics and Gynecology, University of Helsinki and Helsinki University Hospital, Helsinki, Finland \\ Received 13 February 2017; revised 18 July 2017; accepted 23 July 2017
}

\begin{abstract}
Objective: To compare levonorgestrel (LNG) 52-mg intrauterine system (IUS) expulsion rates with fast-track ( $\leq 3$ days) or delayed (2-4 weeks) insertion following mifepristone and misoprostol medical abortion.

Study design: In this pilot trial, we randomized 108 women at $\leq 63$ days' gestation to fast-track $(n=55)$ or delayed $(n=53)$ insertion. Followup visits occurred at 2-4 weeks, 3 months and 1 year. We assessed total and partial expulsion at 3 months and 1 year, adverse effects and bleeding profiles.

Results: We had follow-up data at 3 months and 1 year for $41(74.5 \%)$ and $37(69.8 \%)$ women in the fast-track group and 31 (56.4\%) and 28 $(52.8 \%)$ women in the delayed group. By 3 months, expulsion occurred in six $(12.5 \%)$ women after fast-track and one $(2.3 \%)$ woman after delayed insertion [risk ratio (RR) 5.50, 95\% confidence interval (CI) $0.69-43.90$ ]; most $(n=5)$ of these were partial expulsions in the fasttrack group. By 1 year, expulsion had occurred in seven (14.6\%) and five (11.5\%) women in the fast-track and delayed groups, respectively (RR 1.28, 95\% CI 0.44-3.75). We found no differences in rates of vacuum aspiration, residual tissue, infection and bleeding or bleeding patterns within 3 months of insertion.

Conclusion: Fast-track insertion of the LNG 52-mg IUS after medical abortion is feasible but may result in higher expulsion rates compared to delayed insertion. Due to lack of statistical power and high lost-to-follow-up rates, we were unable to fully address this question.

Implications: Fast-tract initiation of LNG 52-mg IUS contraception after medical abortion is feasible. It results in higher expulsion rates than delayed insertion but may improve postabortal intrauterine contraception uptake.
\end{abstract}

(C) 2017 Elsevier Inc. All rights reserved.

Keywords: Medically induced abortion; Contraception; Contraceptive devices; Intrauterine devices

\section{Introduction}

The proportion of medical abortions varies from $23 \%$ in the United States to over 55\% in England and Wales, $81 \%$ in Scotland, 91\% in Sweden and 96\% in Finland [1-4]. While long-acting reversible contraceptives, including intrauterine devices (IUDs) and contraceptive implants, are most effective in unwanted pregnancy prevention [5-8], the high prevalence of medical abortion use raises the question of the IUD insertion timing. IUD insertion immediately after surgical abortion is safe and effective [9-12]. IUDs are conventionally inserted a few weeks after medical abortion. However, up to half of the women do not attend follow-up

\footnotetext{
* Corresponding author.

E-mail address: oskari.heikinheimo@helsinki.fi (O. Heikinheimo).
}

appointments and are likely to miss effective contraception $[13,14]$. According to study conducted by Sääv et al., a shorter delay (approximately 1 week) between medical abortion and IUD insertion resulted in better IUD uptake compared to conventional delay (3-4 weeks) [15]. Moreover, as ovulation returns at approximately 3 weeks after medical abortion [16], early IUD insertion would ensure effective contraceptive initiation.

Early IUD insertion within approximately 1 week after first-trimester medical abortion shows $7 \%-12 \%$ expulsion rates $[15,17,18]$, with no major complications related to early IUD insertion. However, there are no reports concerning quicker IUD insertion after early medical abortion or as regards use of the levonorgestrel-releasing intrauterine system (LNG-IUS) only.

The aim of our randomized pilot trial was to compare LNG 52-mg IUS expulsion rates at 3 months following 
fast-track (within 3 days) vs. delayed (2-4 weeks) insertion after medical abortion.

\section{Material and methods}

\subsection{Study design}

In this prospective randomized pilot trial, we compared the feasibility and outcomes of fast-track ( $\leq 3$ days after misoprostol) and delayed (2-4 weeks after misoprostol) LNG 52-mg IUS (Mirena ${ }^{\circledR}$; Bayer, Turku, Finland) insertion following medical abortion. We hypothesized that expulsion rates do not differ by more than $20 \%$ between the groups. Thus, the primary outcome was the total or partial expulsion rate of LNG-IUS within 3 months. The secondary outcomes were the expulsion rates within 1 year, infection and surgical completion rates, bleeding problems and bleeding patterns.

We conducted the trial at the Department of Obstetrics and Gynecology, Helsinki University Hospital, Finland, and obtained approval from the Ethics Committee and the Hospital District of Helsinki and Uusimaa. We followed the Declaration of Helsinki principles and registered the study at www.clinicaltrials.gov on December 13, 2012 (NCT01755715).

\subsection{Participants}

We recruited $\geq 18$-year old women requesting medical abortion, having $\leq 63$ days of gestation and planning postabortal LNG-IUS. We excluded women with uterine abnormalities, uterine or cervical neoplasias, or acute pelvic infection. Other contraindications for the LNG-IUS, such as acute liver diseases or prior breast cancer, did not exist among the women assessed for eligibility. We obtained a written informed consent before enrolment. Recruitment occurred from January 30, 2013, to May 17, 2013.

\subsection{Randomization and masking}

We randomized the participants in a 1:1 allocation ratio to fast-track or delayed LNG-IUS insertion at the time of abortion after the determination of gestational age and postabortal contraception planning. We used a computer-generated block randomization list with block sizes of 4 and 6 and sequentially numbered opaque envelopes. The personnel responsible for generating the randomization list and sealing the envelopes did not take part in patient enrolment.

\subsection{Procedures}

All procedures were performed according to Finnish National guidelines on induced abortion [19]. Gestational age was determined by ultrasonography. The women received mifepristone (Mifepristone Linepharma ${ }^{\circledR}$; Linepharma, France), $200 \mathrm{mg}$ orally, and all women self-administered misoprostol $800 \mathrm{mcg}$ vaginally at home $\left(\right.$ Cytotec $^{\circledR}$; Pfizer,
Great Britain) 24-72 h later. A follow-up visit at 2-4 weeks was scheduled.

Fast-track LNG-IUS insertion occurred within 3 days (i.e., on the next working day) after misoprostol administration. Vaginal ultrasonography was performed to ensure gestational sac expulsion and to measure endometrial thickness to exclude clear signs of remaining products of conception. Also, uterine sound measure was recorded. We used the insertion technique recommended by the manufacturer and verified a fundal location using ultrasonography. We asked for insertion pain immediately after the insertion using a numeric rating scale of 0 (no pain) to 10 (the most severe pain imaginable). If vacuum aspiration was performed according to clinical judgment (no predefined criteria) in the fast-track-insertion group, the LNG-IUS was inserted during the procedure.

At the 2-4-week follow-up visit, we confirmed the LNG-IUS location in the fast-track-insertion group and measured fundal endometrial thickness in both groups by ultrasonography. At this follow-up, we inserted the LNG-IUS in the delayed-insertion group. If vacuum aspiration was performed at the time of follow-up, the LNG-IUS was inserted during the procedure. The three investigators performed all insertions. Our experience in LNG-IUS insertion is more than 10 (R.K.) or 20 years (M.M. and O.H.).

The women recorded their uterine bleeding during a 90-day period after abortion. A three-point-scale bleeding chart was used (heavy bleeding, bleeding or spotting). Heavy bleeding was described as a need for the largest sanitary towels during the day, or overflow at night; bleeding as a need of a normal sanitary towel or tampon; and spotting as the need of a panty liner or small tampon, or no need for sanitary protection.

The next follow-up visit was 3 months after insertion. At this visit, the research nurse checked for the presence and appropriate length of the LNG-IUS threads. A researcher performed ultrasonography if LNG-IUS strings were not visible or appeared to be too long.

At the last follow-up visit 1 year after abortion, we performed a pelvic examination and vaginal ultrasonography to verify the LNG-IUS location. We recorded possible complications at every follow-up visit. In cases of no show, the research nurse tried to contact the woman by calling or text messaging two to three times. We reviewed the electronic patient files to compensate for the dropout rate and maximize the information.

We defined LNG-IUS expulsion as "total" when it was spontaneously and completely expelled from the uterus and "partial" if part of the LNG-IUS was visible in the cervix or if the LNG-IUS stem was seen in the cervix in ultrasonography. If LNG-IUS was totally expelled, a new LNG-IUS was offered and inserted free of charge. Also, partial expulsion resulted in removal and new LNG-IUS insertion free of charge. Infection diagnosis was based on clinical judgment only and defined as antibiotics treatment because of uterine tenderness noted in clinical examination, and/or purulent cervical discharge or fever. 


\subsection{Statistical analysis}

The sample size calculation was based on the reported expulsion rate (including both total and partial expulsions) of $8 \%$ following postabortal insertion $[9,14,15]$. We considered a relative difference of $\leq 20 \%$ to be insignificant based on clinical judgment only for this pilot evaluation. Using a binary outcome calculator and assuming an alpha level of 0.05 for a two-sided test, a number of 48 subjects per group would result in $95 \%$ power [20]. A loss to follow-up of $4 \%$ was anticipated; we planned to recruit 50 patients per group. We performed intention-to-treat and per-protocol analyses. Categorical data were analyzed and risk ratios (RRs) calculated by cross-tabulation, and statistical significance was calculated by using Fisher's Exact Test. The MannWhitney $U$ test was used for continuous variables. All analyses were performed with IBM SPSS statistical software versions 22 and 24.

\section{Results}

\subsection{Study participants}

Altogether, 108 women undergoing medical abortion having gestational age $\leq 63$ days were randomized to the trial. The fast-track-insertion group included 55 women and the delayed-insertion group 53 women according to intention-to-treat analysis (Fig. 1). Randomization did not result in any significant differences between the study groups (Table 1).

The LNG-IUS insertion occurred in $51(92.7 \%)$ vs. 47 $(88.7 \%)$ cases in the fast-track and the delayed-insertion groups (RR 1.05, 95\% confidence interval [CI] 0.93-1.18, $\mathrm{p}=.52$ ). The LNG-IUS insertions were carried out per protocol (only after uncomplicated medical abortion and within 3 days in the fast-track and 2-4 weeks in the delayed insertion group) in $48(94.1 \%)$ cases in the fast-track and in $44(93.6 \%)$ cases in the delayed-insertion group (RR 1.01, 95\% CI $0.94-1.09, \mathrm{p}=.82)$. Two $(3.6 \%)$ vs. three $(5.7 \%)$ women received LNG-IUS at vacuum aspiration (RR 0.64, $95 \%$ CI $0.11-3.69, \mathrm{p}=.68$ ).

Altogether, $50(90.9 \%)$ vs. $49(92.5 \%)$ women in the fast-track-insertion and delayed-insertion groups attended the 2-4-week follow-up visit (RR $0.98,95 \%$ CI $0.88-1.10$, $\mathrm{p}=1.00)$, and $41(74.5 \%)$ and $32(60.4 \%)$ women attended the 3-month follow-up visit (RR 1.23, 95\% CI 0.95-1.61, p= $.15)$, respectively. Attendance at 1 year was 37 (67.3\%) vs. 28 (52.8\%) (RR 1.27, 95\% CI 0.93-1.74, p=.17). LNG-IUS continuation, expulsion or removal status was known after reviewing clinical records in $43(78.2 \%)$ vs. $33(62.3 \%)$

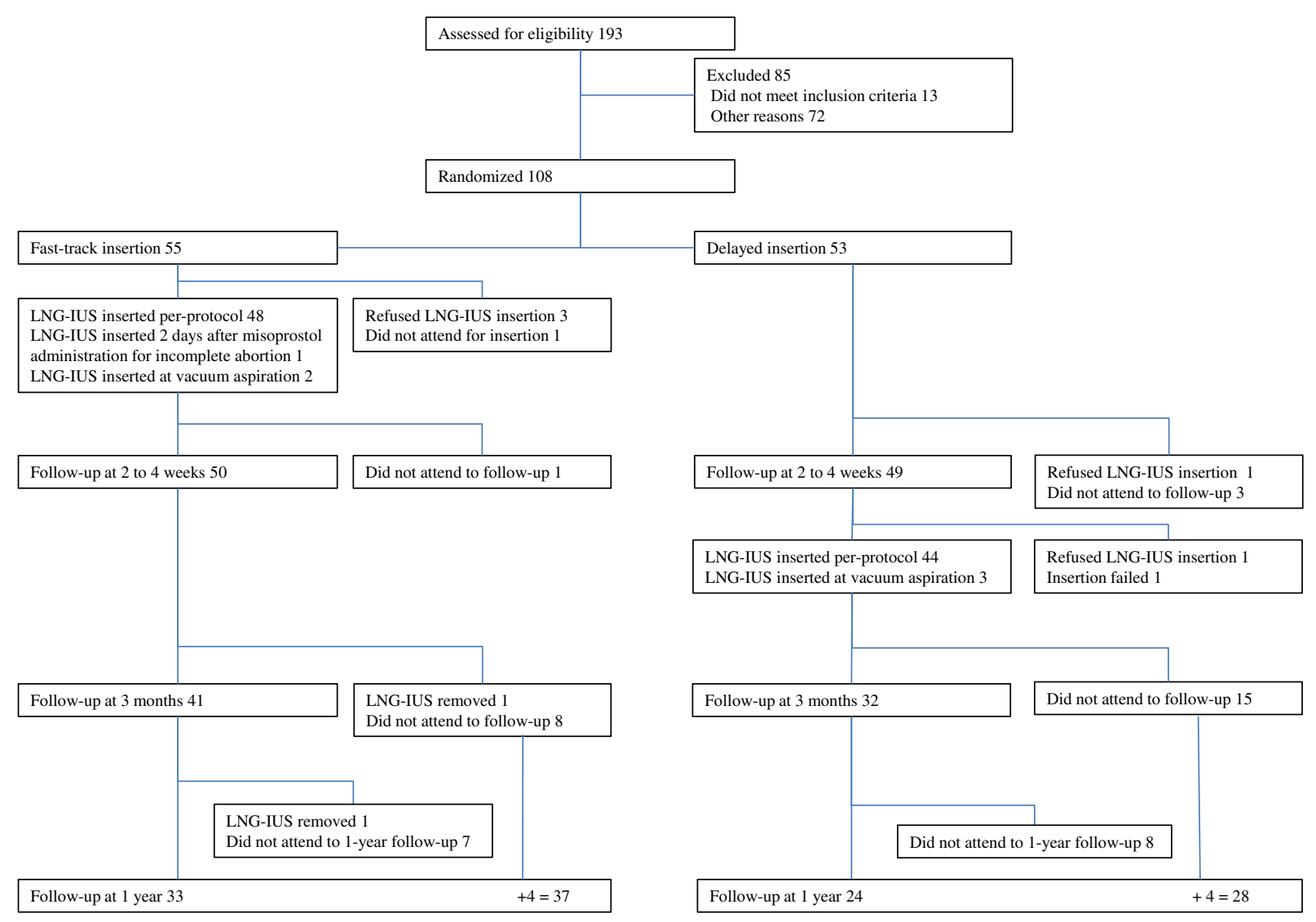

Fig. 1. Randomization and follow-up of women undergoing a medical abortion and a fast-track ( $\leq 3$ days) or delayed (2-4 weeks) LNG-IUS insertion after the abortion. 
Table 1

Demographics of the study participants undergoing fast-track ( $\leq 3$ days) or delayed LNG-IUS insertion (2-4 weeks) after medical abortion: intention-to-treat analysis

\begin{tabular}{lll}
\hline & Fast-track insertion $n=55$ & Delayed insertion $n=53$ \\
\hline Gestational age (days) & $48(45-56)$ & $50(47-57)$ \\
Age (years) & $29(24-35)$ & $29(24-34)$ \\
BMI & $23(21-26)$ & $23(21-27)$ \\
History of pregnancy & $36(65.5 \%)$ & $39(73.6 \%)$ \\
History of delivery & $31(56.4 \%)$ & $32(60.4 \%)$ \\
History of abortion & $18(32.7 \%)$ & $23(43.4 \%)$ \\
Marital status & & \\
$\quad$ Single & $25(45.5 \%)$ & $27(50.9 \%)$ \\
$\quad$ Cohabiting & $13(23.6 \%)$ & $12(22.6 \%)$ \\
$\quad$ Married & $9(16.4 \%)$ & $10(18.9 \%)$ \\
$\quad$ Divorced & $5(9.1 \%)$ & $3(5.7 \%)$ \\
$\quad$ Unknown & $3(5.5 \%)$ & $1(1.9 \%)$ \\
Smokers & $25(45.5 \%)$ & $29(54.7 \%)$ \\
Regular use of alcohol & $38(69.1 \%)$ & $39(73.6 \%)$ \\
\hline
\end{tabular}

Data are presented as median (interquartile range), or $n(\%)$. BMI, body mass index $\left(\mathrm{kg} / \mathrm{m}^{2}\right)$.

cases at 3 months (RR 1.26, 95\% CI 0.98-1.62, p=.09) and in $41(74.5 \%)$ vs. $30(65.6 \%)$ cases at 1 year (RR 1.32, 95\% CI $0.99-1.75, \mathrm{p}=.07)$.

At the time of LNG-IUS insertion, the sound measure and endometrial thickness were greater in the fast-track-insertion group, but endometrial thickness decreased to similar level compared to delayed-insertion group at the time of the 2-4-week follow-up (Table 2). Insertion pain and insertion problems did not differ between the groups.

\subsection{Expulsions}

The LNG-IUS expulsion rates at 3 months and 1 year are presented in Table 3. In intention-to-treat analysis, the partial expulsion rate at 3 months was higher $[6(10.9 \%)$ vs. 0 $(0.0 \%)]$ in the fast-track-insertion group $(p=.03)$. In per-protocol analysis, the corresponding figures were 5 $(10.4 \%)$ vs. $0(0.0 \%)(p=.06)$, respectively.

Total LNG-IUS-expulsions were diagnosed mostly $(n=2)$ during additional visits because of bleeding problems within 3 months after abortion. One total expulsion was noticed at a request for a subsequent abortion at 9 weeks of gestation 6 months after the index abortion on a woman, who did not attend her 3-month follow-up visit.

In the fast-track-insertion group, partial expulsions were noted at the 2-4-week follow-up visit $(n=6)$ or 1-year visit $(n=1)$. The partial expulsions were mostly asymptomatic and diagnosed by ultrasonography $(n=4,57 \%)$. In the delayed-insertion group, all three partial expulsions were diagnosed at 1 -year visit and two (67\%) were diagnosed by ultrasonography.

\subsection{Secondary outcomes}

No serious complications occurred during LNG-IUS insertion. Table 4 shows adverse events following medical abortion (intention-to-treat analysis). Uterine vacuum aspi-
Table 2

Results at the time of the LNG-IUS insertion and at the 2-4-week follow-up following fast-track ( $\leq 3$ days) or delayed insertion ( $2-4$ weeks) of LNG-IUS after medical abortion: per-protocol analysis

\begin{tabular}{|c|c|c|c|}
\hline & $\begin{array}{l}\text { Fast-track } \\
\text { insertion } n=48\end{array}$ & $\begin{array}{l}\text { Delayed } \\
\text { insertion } n=44\end{array}$ & $\begin{array}{l}\mathrm{p} \\
\text { value }\end{array}$ \\
\hline $\begin{array}{l}\text { Interval from 1st } \\
\text { misoprostol administration to } \\
\text { LNG-IUS insertion (h) }\end{array}$ & $49(29-61)$ & $421(345-473)$ & $<.01$ \\
\hline $\begin{array}{l}\text { Sound measurement before } \\
\text { LNG-IUS insertion }(\mathrm{cm})\end{array}$ & $9.0(8.5-9.9)$ & $8.0(7.5-9.0)$ & $<.01$ \\
\hline $\begin{array}{l}\text { Pain score at LNG-IUS } \\
\text { insertion (NRS) }\end{array}$ & $4.0(2.5-6.9)$ & $4.0(3.0-6.0)$ & .62 \\
\hline Problems with insertion ${ }^{\mathrm{a}}$ & $1(2.1 \%)$ & $3(6.8 \%)$ & .35 \\
\hline $\begin{array}{l}\text { Endometrial thickness }^{\mathrm{b}} \\
\text { before LNG-IUS insertion (mm) }\end{array}$ & $14.3(11.7-17.0)$ & $9.0(6.0-12.5)$ & $<.01$ \\
\hline $\begin{array}{l}\text { Endometrial thickness }{ }^{\mathrm{b}} \text { at } \\
\text { 2-4-week follow-up }(\mathrm{mm})^{\mathrm{c}}\end{array}$ & $7.3(5.2-13.0)$ & $9.0(6.0-12.5)$ & .34 \\
\hline
\end{tabular}

Data are presented as median (interquartile range) unless otherwise stated. NRS, numeric rating scale from 0 (no pain) to 10 (strongest pain imaginable).

${ }^{\text {a }}$ First LNG-IUS misplaced or insertion failed, need for cervical dilatation, abnormal pain, vasovagal or panic symptoms, insertion delayed due to residua or endometritis. Data are number of cases (\%).

b "Endometrial thickness" may in some cases include blood and small amount of remained products of conception.

c $n=46$ vs. 44 .

ration within 4 days following the first misoprostol administration was performed in two (3.6\%) cases in the fast-track-insertion group (one incomplete abortion and one case of heavy bleeding). One woman with residual tissue and bleeding in the fast-track-insertion group compared to three women with residual tissue and bleeding and one woman with infection in the delayed-insertion group had a later procedure (more than 4 days after abortion) (RR 0.24, 95\% CI $0.03-2.09, \mathrm{p}=.20)$. Two women $(3.6 \%)$ received misoprostol due to partly retained products of conception in the fast-track-insertion group.

All diagnosed infections [6 (10.9\%) vs. 3 (5.7\%), RR 1.93, 95\% CI 0.51-7.31, $\mathrm{p}=.49$ ] were mild cervicitis or endometritis and treated with oral antibiotics. In the fast-track-insertion group, one LNG-IUS was expelled during bleeding at the time of infection diagnosis, but no LNG-IUS was removed because of infection. In the delayed-insertion group, all infections were diagnosed before LNG-IUS insertion. Altogether, 13 (23.6\%) women in the fast-track and $11(20.8 \%)$ women in the delayed-insertion group had problems associated with the abortion leading to additional contact or intervention (RR $1.14,95 \%$ CI $0.55-2.31, \mathrm{p}=.82$ ).

In the per-protocol population, $35(63.6 \%)$ and 30 $(56.6 \%)$ women in the fast-track and delayed-insertion groups returned appropriately filled bleeding diaries $(p=$ .56). Bleeding patterns and profiles are presented in Table 5 and Fig. 2. The first bleeding episode was slightly longer in the fast-track-insertion group because of an increased number of spotting days. However, the overall number of bleeding days did not differ between the study groups during 
Table 3

Expulsions of the LNG-IUS by 3 months and 1 year following fast-track ( $\leq 3$ days) or delayed insertion ( $2-4$ weeks) after medical abortion

\begin{tabular}{|c|c|c|c|c|c|c|c|c|}
\hline & \multicolumn{4}{|c|}{ Intention-to-treat analysis } & \multicolumn{4}{|c|}{ Per-protocol analysis } \\
\hline & $\begin{array}{l}\text { Fast-track } \\
\text { insertion } n=55\end{array}$ & $\begin{array}{l}\text { Delayed } \\
\text { insertion } n=53\end{array}$ & $\begin{array}{l}\text { RR } \\
(95 \% \mathrm{CI})\end{array}$ & $\mathrm{p}$ value & $\begin{array}{l}\text { Fast-track } \\
\text { insertion } n=48\end{array}$ & $\begin{array}{l}\text { Delayed } \\
\text { insertion } n=44\end{array}$ & $\begin{array}{l}\text { RR } \\
(95 \% \mathrm{CI})\end{array}$ & $\mathrm{p}$ value \\
\hline \multicolumn{9}{|c|}{ Expulsion total or partial } \\
\hline 3 months & $7(12.7 \%)$ & $1(1.9 \%)$ & $6.75(0.86-52.98)$ & .06 & $6(12.5 \%)$ & $1(2.3 \%)$ & $5.50(0.69-43.90)$ & .11 \\
\hline 1 year & $8(14.5 \%)$ & $5(9.4 \%)$ & $1.54(0.54-4.41)$ & .56 & $7(14.6 \%)$ & $5(11.4 \%)$ & $1.28(0.44-3.75)$ & .76 \\
\hline \multicolumn{9}{|c|}{ Expulsion total } \\
\hline 3 months & $1(1.8 \%)$ & $1(1.9 \%)$ & $0.96(0.06-15.01)$ & 1.00 & $1(2.1 \%)$ & $1(2.3 \%)$ & $0.92(0.06-14.22)$ & 1.00 \\
\hline 1 year & $1(1.8 \%)$ & $2(3.8 \%)$ & $0.48(0.05-5.16)$ & .61 & $1(2.1 \%)$ & $2(4.5 \%)$ & $0.46(0.04-4.88)$ & .61 \\
\hline \multicolumn{9}{|c|}{ Expulsion partial } \\
\hline 3 months & $6(10.9 \%)$ & $0(0.0 \%)$ & Not applicable & .03 & $5(10.4 \%)$ & $0(0.0 \%)$ & Not applicable & .06 \\
\hline 1 year & $7(12.7 \%)$ & $3(5.7 \%)$ & $2.25(0.61-8.24)$ & .32 & $6(12.5 \%)$ & $3(6.8 \%)$ & $1.83(0.49-6.89)$ & .49 \\
\hline
\end{tabular}

the 90-day reference period. To assess the validity of returned diaries, the women who returned them were compared with those who did not in regard to their demographic background factors and insertion data, and both groups were similar. Insertion problems and pain scores did not affect the return rates.

\section{Discussion}

We found that fast-track insertion of LNG-IUS following early medical abortion may result in higher expulsion rates in comparison to delayed insertion at 3 months. Significant difference between long-term LNG-IUS expulsion rates

Table 4

Complications by 3 months following fast-track ( $\leq 3$ days) or delayed ( $2-4$ weeks) insertion of the LNG-IUS after medical abortion: intention-to-treat analysis

\begin{tabular}{|c|c|c|c|c|}
\hline & $\begin{array}{l}\text { Fast-track } \\
\text { insertion } \\
n=55\end{array}$ & $\begin{array}{l}\text { Delayed } \\
\text { insertion } \\
n=53\end{array}$ & $\begin{array}{l}\text { RR } \\
(95 \% \mathrm{CI})\end{array}$ & $\mathrm{p}$ value \\
\hline $\begin{array}{l}\text { Early surgical } \\
\text { operation }^{\mathrm{a}}\end{array}$ & $2(3.6 \%)$ & $0(0 \%)$ & Not applicable & .50 \\
\hline $\begin{array}{l}\text { Later surgical } \\
\text { operation }^{\mathrm{b}}\end{array}$ & $1(1.8 \%)$ & $4(7.5 \%)$ & $0.24(0.03-2.09)$ & .20 \\
\hline Residua $^{c}$ & $3(5.5 \%)$ & $4(7.5 \%)$ & $0.72(0.17-3.08)$ & .71 \\
\hline $\begin{array}{l}\text { Residua } \\
\text { (medicated only) }\end{array}$ & $2(3.6 \%)$ & $0(0.0 \%)$ & Not applicable & .50 \\
\hline Infection & $6(10.9 \%)$ & $3(5.7 \%)$ & $1.93(0.51-7.31)$ & .49 \\
\hline Bleeding problem ${ }^{\mathrm{d}}$ & $3(5.5 \%)$ & $5(9.4 \%)$ & $0.58(0.15-2.30)$ & .49 \\
\hline Any problem ${ }^{\mathrm{e}}$ & $13(23.6 \%)$ & $11(20.8 \%)$ & $1.14(0.56-2.31)$ & .82 \\
\hline
\end{tabular}

${ }^{a}$ Vacuum aspiration/surgical evacuation of the uterus performed immediately at hospital because of heavy bleeding, or failed or incomplete abortion.

${ }^{b}$ Vacuum aspiration or hysteroscopy $>4$ days of abortion because of incomplete abortion, bleeding problem and/or clinical infection.

${ }^{c}$ Residual tissue treated by means of medication (administration of additional misoprostol) or surgical evacuation.

${ }^{\mathrm{d}}$ Bleeding problem resulting in additional contact or intervention (medication, surgical evacuation, blood transfusion).

e Any problem associated with abortion or LNG-IUS leading to additional contact or intervention. following the fast-track and delayed insertion could not be shown, but limited conclusions should be drawn because of low number of women and high lost-to-follow-up rate. The results remained essentially similar in the per-protocol analysis limited to women receiving the LNG-IUS after uncomplicated medical abortion within the predefined timetable. The overall complication rates and bleeding profiles did not differ significantly between the study groups. No serious adverse events related to LNG-IUS insertion occurred. Importantly, immediate LNG-IUS insertion did not increase the risk of retained products of conception.

Table 5

Bleeding profiles during the 90-day reference period following immediate ( $\leq 3$ days) or delayed insertion (2-4 weeks) of the LNG-IUS after medical abortion (reference period was initiated from the day of first misoprostol administration): per-protocol analysis

\begin{tabular}{lcll}
\hline & $\begin{array}{l}\text { Fast-track } \\
\text { insertion } \\
n=35\end{array}$ & $\begin{array}{l}\text { Delayed } \\
\text { insertion } \\
n=30\end{array}$ & p value \\
\hline $\begin{array}{l}\text { First bleeding or spotting } \\
\text { episode (days) }\end{array}$ & $26(17-57)$ & $17(13-47)$ & .03 \\
Heavy bleeding (days) & $2(1-4)$ & $3(0-5)$ & .73 \\
Bleeding (days) & $10(5-18)$ & $7(4-13)$ & .20 \\
Spotting (days) & $13(6-36)$ & $8(3-14)$ & .03 \\
Bleeding or spotting & $49(33-69)$ & $41(35-56)$ & .18 \\
days/90 days (days) & & & \\
Heavy bleeding (days) & $2(1-4)$ & $3(0-7)$ & .33 \\
Bleeding (days) & $12(9-23)$ & $14(9-20)$ & .88 \\
$\quad$ Spotting (days) & $30(14-46)$ & $22(15-29)$ & .10 \\
Number of bleeding and/or & $3(2-5)$ & $4(2-6)$ & .45 \\
$\quad$ spotting episodes & & & \\
$\begin{array}{l}\text { Number of bleeding only episodes } \\
\text { Number of spotting only episodes }\end{array}$ & $0(0-0)$ & $0(0-0)$ & .12 \\
Number of bleeding or spotting & $12(8-29)$ & $1(0-3)$ & .76 \\
$\quad$ days/episode (days) & & & .32 \\
\hline
\end{tabular}

Data are presented as median (interquartile range).

Heavy bleeding was described as the need of the largest available sanitary towel during the day, or overflow at night; bleeding as the need of a normal sanitary towel or tampon; and spotting as the need of a panty liner or small tampon, or no need of sanitary protection. 


\section{Fasttrack insertion}

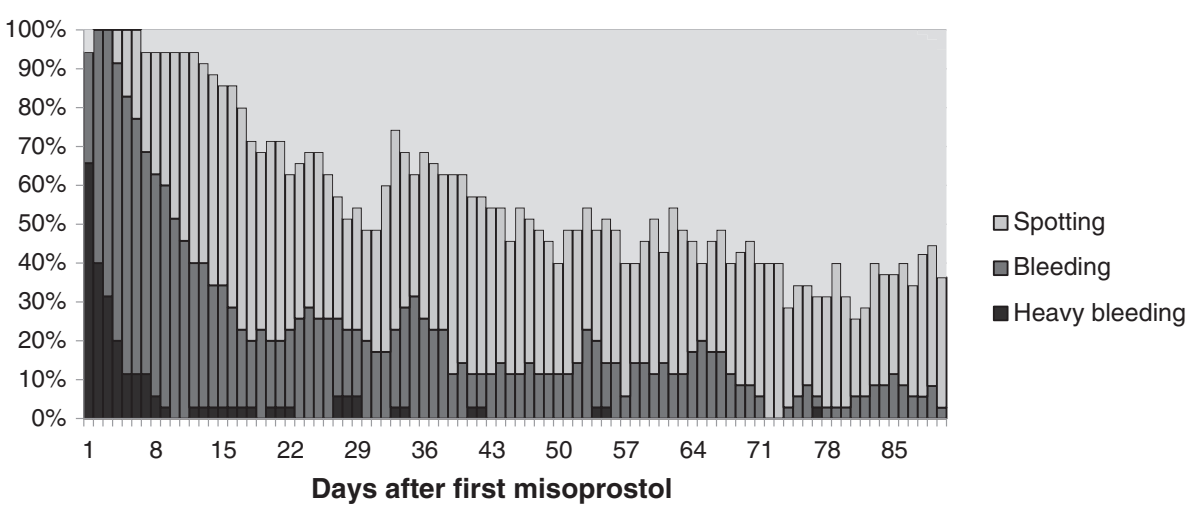

\section{Delayed insertion}

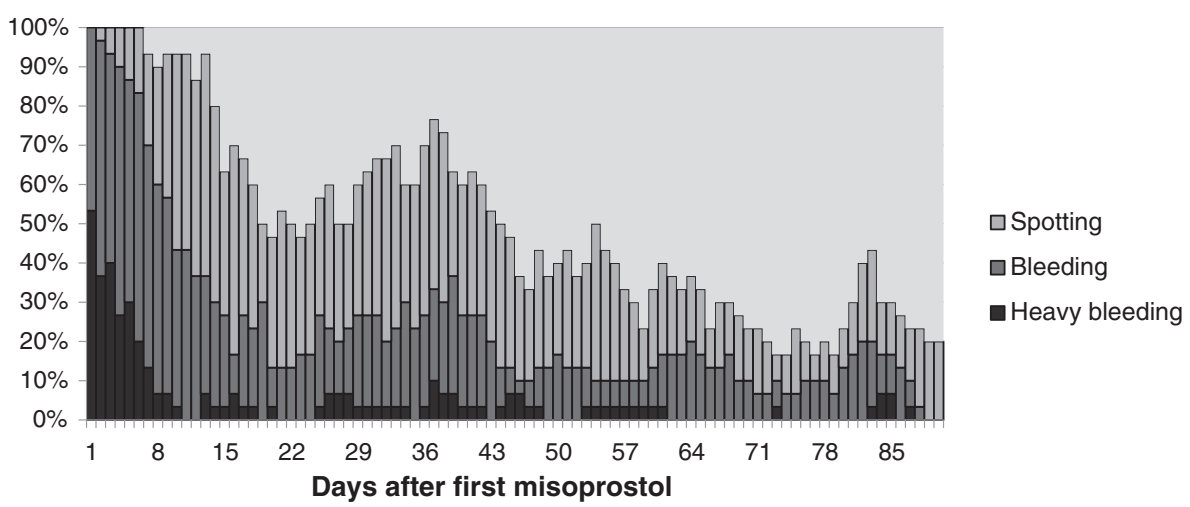

Fig. 2. Bleeding profiles according to randomization group after fast-track ( $\leq 3$ days) or delayed (2-4 weeks) LNG-IUS insertion following medical abortion; per-protocol analysis.Heavy bleeding was described as the need of large sanitary towels during the day, or overflow at night; bleeding as the need of normal sanitary towels or tampons; and spotting as the need of panty liners or small tampons, or no need of sanitary protection.

Our total and partial LNG-IUS expulsion rates following fast-track insertion after early medical abortion were comparable to those reported in previous studies concerning IUD insertion within 1 week after medical abortion $[14,15,17,18]$. Following IUD insertion at first-trimester surgical abortion, expulsion rates have been $3.4 \%$ within 6 months [21] and $0.8 \%-7.1 \%$ within 12 months [9,22-24]. However, the lowest expulsion rates are based on retrospective register data or phone calls, which may underestimate values. It is noteworthy that the present partial expulsion rate might have been overestimated, as most diagnoses were based on routine ultrasonography, not on clinical symptoms. Furthermore, also cervically placed LNG-IUS has a contraceptive effect [25]; thus, some removals and reinsertions might have been unnecessary.

The rate of clinically diagnosed infections was relatively high $-10.9 \%$ in the fast-track vs. $5.7 \%$ in the delayed-insertion group. However, the infection diagnosis was based on liberal clinical judgment only. Infections in the delayed-insertion group were diagnosed and treated before LNG-IUS insertion and were not related to the insertion. In previous studies concerning IUD insertion after early medical abortion, no postinsertion infections have been diagnosed. However, the insertions occurred at the earliest at 1 week after abortion, and infection at the time of insertion was an exclusion criterion in those trials $[15,17,18]$. In addition, infection prophylaxis (doxycycline orally twice a day for 1 week) was used in the study by Shimoni et al. [18]. In Finnish register-based studies, the infection rate after first-trimester medical abortion has been $1.4 \%$ [26,27]. In our previous randomized trial, the infection rates after first-trimester medical abortion were $5.7 \%$ and $9.4 \%$ during the 3-month follow-up period [28]. The similar infection rates seen in our study groups suggest that the infections were related to medical abortion itself and not to the immediate provision of the LNG-IUS. Also, as part of the clinical trial, the women had easy access to consultation and treatment, which might have led to some overdiagnosis.

The bleeding patterns during the 90-day reference period were indistinguishable following fast-track insertion and delayed LNG-IUS insertion. The endometrium was thicker at the time of fast-track insertion, but at the 2-4-week follow-up visit, measurements were similar in both groups. This suggests that postabortal endometrium responds rapidly 
to intrauterine administration of LNG. Sääv et al. reported similar results after early medical abortion [15]; the endometrium was thicker in the early-insertion group and more bleeding days appeared during the first 4 weeks compared to the delayed-insertion group, but fewer heavy bleeding days occurred at 6 months.

A strength of our study is its randomized design, but the dropout rates were higher than presumed. However, the patients were advised to contact the hospital if experiencing problems concerning the abortion or the LNG-IUS. Complications associated with induced abortion are mostly treated at public hospitals in Finland, and we at our hospital are in charge of abortion care in the Helsinki metropolitan area. Hence, the patients' clinical records would have revealed all serious abortion-related complications.

In this single-center randomized trial, we assumed that fast-track and delayed LNG-IUS insertion would be similar with regards to expulsion rates, and our power calculation was based on this hypothesis. However, our results showed that this was only partially true; total expulsion rates were comparable, but partial expulsion rates were higher among the fast-track group. This is partly due to ultrasonography use, which is likely to result into overdiagnosis of partially displaced LNG-IUS. No significant differences in the secondary outcomes between one treatment method over the other could be shown. This could be partly due to the chosen method of power calculation and limits the conclusions that can be drawn based on the study.

We conclude that fast-track LNG-IUS provision after medical abortion is feasible despite the increased partial expulsion rate. Thus, fast-track LNG-IUS insertion after medical abortion is an option to ensure intrauterine contraception uptake, but further research is needed to evaluate the benefits and cost-effectiveness of this treatment.

\section{Acknowledgments}

We thank research nurse Pirjo Ikonen for her essential contribution concerning the patients; Pekka Lähteenmäki, M.D., Ph.D., for valuable comments on the manuscript; Pasi Korhonen, Ph.D., of EPID Research Oy for statistical consultation; and Nick Bolton, Ph.D., for language revision.

\section{Funding}

This trial was funded by research funds from the Hospital District of Helsinki and Uusimaa, the Finnish Cultural Foundation and the Finnish-Norwegian Medical Foundation.

\section{Conflicts of interest}

O.H. has served on advisory boards for Bayer Healthcare, Exelgyn, Gedeon Richter and MSD Finland (part of Merck
\& Co. Inc.) and designed and lectured at educational events connected with these companies. The other authors (R.K. and M.M.) have no conflicts of interest to declare.

\section{References}

[1] Jones RK, Jerman J. Abortion incidence and service availability in the United States, 2011. Perspect Sex Reprod Health 2014;46:3-14.

[2] Gov.uk. Abortion statistics, England and Wales: 2015. https://www. gov.uk/government/statistics/report-on-abortion-statistics-in-englandand-wales-for-20152016.

[3] National Institute for Health and Welfare, Official Statistics of Finland. Induced abortions 2015. http://urn.fi/URN:NBN:fi-fe20161020254292016.

[4] Socialstyrelsen, Sverige. Statistik om aborter 2015. http://www. socialstyrelsen.se/publikationer2016/2016-5-202016.

[5] Cameron ST, Glasier A, Chen ZE, Johnstone A, Dunlop C, Heller R. Effect of contraception provided at termination of pregnancy and incidence of subsequent termination of pregnancy. BJOG 2012;119: 1074-80

[6] Heikinheimo O, Gissler M, Suhonen S. Age, parity, history of abortion and contraceptive choices affect the risk of repeat abortion Contraception 2008;78:149-54.

[7] Pohjoranta E, Mentula M, Gissler M, Suhonen S, Heikinheimo O. Provision of intrauterine contraception in association with first trimester induced abortion reduces the need of repeat abortion: firstyear results of a randomized controlled trial. Hum Reprod 2015;30 2539-46

[8] Hognert H, Kopp Kallner H, Cameron S, Nyrelli C, Jawad I, Heller R, et al. Immediate versus delayed insertion of an etonogestrel releasing implant at medical abortion - a randomized controlled equivalence trial. Hum Reprod 2016;31:2484-90, http://dx.doi.org/10.1093/humrep/dew238.

[9] Pakarinen P, Toivonen J, Luukkainen T. Randomized comparison of levonorgestrel- and copper-releasing intrauterine systems immediately after abortion, with 5 years' follow-up. Contraception 2003;68: $31-4$.

[10] Grimes DA, Lopez LM, Schulz KF, Stanwood NL. Immediate postabortal insertion of intrauterine devices. Cochrane Database Syst Rev 2010;6: CD001777, http://dx.doi.org/10.1002/14651858.CD001777.pub3.

[11] Steenland MW, Tepper NK, Curtis KM, Kapp N. Intrauterine contraceptive insertion postabortion: a systematic review. Contraception 2011;84:447-64.

[12] Okusanya BO, Oduwole O, Effa EE. Immediate postabortal insertion of intrauterine devices. Cochrane Database Syst Rev 2014;7: Cd001777, http://dx.doi.org/10.1002/14651858.CD001777.pub4.

[13] Pohjoranta E, Suhonen S, Heikinheimo O. Attendance at post-abortal follow-up visits is low - can the risks of non-attendance be identified? Acta Obstet Gynecol Scand 2011;90:543-6.

[14] Cameron ST, Berugoda N, Johnstone A, Glasier A. Assessment of a 'fasttrack' referral service for intrauterine contraception following early medical abortion. J Fam Plann Reprod Health Care 2012;38:175-8.

[15] Saav I, Stephansson O, Gemzell-Danielsson K. Early versus delayed insertion of intrauterine contraception after medical abortion - a randomized controlled trial. PLoS One 2012;7:e48948, http:// dx.doi.org/10.1371/journal.pone.0048948.

[16] Schreiber CA, Sober S, Ratcliffe S, Creinin MD. Ovulation resumption after medical abortion with mifepristone and misoprostol. Contraception 2011;84:230-3.

[17] Betstadt SJ, Turok DK, Kapp N, Feng KT, Borgatta L. Intrauterine device insertion after medical abortion. Contraception 2011;83: $517-21$.

[18] Shimoni N, Davis A, Ramos ME, Rosario L, Westhoff C. Timing of copper intrauterine device insertion after medical abortion: a randomized controlled trial. Obstet Gynecol 2011;118:623-8. 
[19] The Finnish Medical Society Duodecim. Current care guidelines: abortion. http://www.kaypahoito.fi/web/kh/suositukset/suositus?id= hoi27050.

[20] Sealed Envelope Ltd. Power calculator for binary outcome equivalence trial. http://www.sealedenvelope.com/power/binaryequivalence/. 2012.

[21] Bednarek PH, Creinin MD, Reeves MF, Cwiak C, Espey E, Jensen JT Immediate versus delayed IUD insertion after uterine aspiration. Med 2011;364:2208-17.

[22] Ortayli N, Bulut A, Sahin T, Sivin I. Immediate postabortal contraception with the levonorgestrel intrauterine device, Norplant, and traditional methods. Contraception 2001;63:309-14.

[23] Goodman S, Hendlish SK, Benedict C, Reeves MF, Pera-Floyd M, Foster-Rosales A. Increasing intrauterine contraception use by reducing barriers to post-abortal and interval insertion. Contraception 2008; 78:136-42.
[24] Drey EA, Reeves MF, Ogawa DD, Sokoloff A, Darney PD, Steinauer JE. Insertion of intrauterine contraceptives immediately following firstand second-trimester abortions. Contraception 2009;79:397-402.

[25] Pakarinen P, Luukkainen T, Elomaa K, et al. A 12-month comparative clinical investigation of a levonorgestrel-releasing intracervical device situated in the uterine cavity or cervical canal. Contraception 1996;54:187-92.

[26] Niinimaki M, Suhonen S, Mentula M, Hemminki E, Heikinheimo O, Gissler M. Comparison of rates of adverse events in adolescent and adult women undergoing medical abortion: population register based study. BMJ 2011;342:d2111.

[27] Niinimaki M, Pouta A, Bloigu A, Gissler M, Hemminki E, Suhonen S, et al. Immediate complications after medical compared with surgical termination of pregnancy. Obstet Gynecol 2009;114:795-804.

[28] Pohjoranta E, Suhonen S, Mentula M, Heikinheimo O. Intrauterine contraception after medical abortion: factors affecting success of early insertion. Contraception 2017;95:257-62. 